\title{
9. Millennium Development Goals and the Pacific
}

\author{
Linda Petersen
}

Le Pacifique et les objectifs de développement du millénaire - mise à jour 2009

Cet article présente une vue d'ensemble du rapport de 2004 sur les Objectifs de développement du millénaire (ODM) établie par le Secrétariat de la Communauté du Pacifique (CPS) et le Programme des Nations unies pour le développement (PNUD). Ce rapport constitue une référence utile pour mesurer le développement dans la région du Pacifique insulaire par rapport aux Objectifs de développement du millénaire et aux indicateurs et objectifs qui leur sont associés. Il couvre 15 pays insulaires du Pacifique et donne des indications à la fois sur les pays individuellement et sur la perspective d'ensemble de la région quant aux réalisations des ODM en 2004 avec quelques projections de progrès à l'horizon 2015. On constate que sur la période de six ans, un certain nombre de questions ont influencé les progrès ou constitué une menace pour la réussite du programme et on conclut que les gouvernements des îles du Pacifique doivent changer leur façon de gérer et d'utiliser les ressources ainsi que la façon de présenter les rapports relatifs à cellesci. Ces ressources ne sont pas utilisées de façon aussi efficace qu'elles le pourraient et en outre elles ne bénéficient pas à ceux qui en ont le plus besoin, à savoir le nombre croissant de pauvres et de démunis dans nos pays, y compris ceux qui, dans les zones rurales et les îles excentrées, ne disposent pas de services et qui n'ont pas les occasions de gagner leur vie et de parvenir au bien-être. Pour qu'un changement intervienne, les gouvernements doivent concentrer leurs efforts sur la façon de faire parvenir ces ressources et ces services à ces personnes. Ceci devrait être une priorité. Les pays doivent mettre en pratique leur engagement politique et leur détermination afin d'accomplir cette tâche dans leur contexte propre en consultant leur population et les acteurs du développement. 
Politics, Development and Security in Oceania

\section{Introduction}

Since signing up to and endorsing the Millennium Declaration in 2000, Pacific island countries have - some more than others - used the Millennium Development Goals (MDG) as a measure of development progress both at national and regional level. United Nations development agencies working in the Pacific have been the main driving force for using the MDG to measure and track development progress in the Pacific but more recently, there has been a stronger push from the larger metropolitan Pacific countries towards this approach, in particular Australia.

This brief paper provides an overview of the regional MDG 2004 report compiled by the Secretariat of the Pacific Community (SPC) and the United Nations Development Program (UNDP) which provided a useful baseline for measuring development in the Pacific island region against the Millennium Development Goals and their associated indicators and targets (Secretariat of the Pacific Community 2004). It covered 15 Pacific island nations and provided both an individual country and overall regional perspective on MDG achievements in 2004 with some projections of progress to 2015.

Since then most countries have produced an initial MDG report and many have integrated MDG targets and indicators into their national development plans. A few countries have gone as far as to begin to assess what it will cost to achieve the MDG by 2015. There have also been subsequent regional assessments most recently by the Australian Government, in the August 2009 AusAID report, Tracking development and governance in the Pacific. This paper will also comment on where we are today six years on and provide some reflection on some of the issues influencing progress or threatening success.

\section{The Millennium Development Goals}

The global focus on the MDG has often overshadowed the Millennium Declaration which provides the glue that binds the goals together. The Declaration while recognising the role of individual countries and societies in achieving the MDG, puts emphasis on collective responsibility, principles of human dignity, equality and equity, the duty and the responsibility of leaders to all the worlds' people especially the most vulnerable and particular children and future generations. The Declaration is a commitment to the right to development, to peace and security, gender equality, the eradication of many dimensions of poverty and sustainable human development for all of the world's people. If each goal is mapped against this overall vision for countries and the world it becomes easier to understand and appreciate that they all linked in one way or another. 
The Millennium Development Goals - the eight goals with their respective targets and indicators - present a challenge to the world to accelerate the pace of development while testing political commitment. For developing countries achievement demands policy reforms and strengthened governance while for the developing world new aid commitments, equitable trading rules and debt relief through mobilising stronger partnerships and resource; initiating propoor policy reforms, institutional change and budget allocations; and improve monitoring of social indicators.

\section{The Pacific Islands Regional Millennium Development Goals Report, 2004, SPC/UNDP}

The report was endorsed by Forum Economic Ministers and a product of the UN/CROP MDG working group which was formed in 2004 to assist with the integration of the MDG into Pacific island country development goals and strategies. It was intended to supplement national reports being prepared by countries as part of the first comprehensive review of MDG progress conducted the UN. The report was produced in consultation and with the participation of countries. The findings are summarised below.

\section{Millennium Development Goal 1: Halving Hunger and Poverty}

At the time poverty related data was found to be incomplete but suggested that poverty was increasing in a number of countries. When this data is combined with data on participatory poverty and hardships assessments carried out by ADB and the UNDP, the picture is of a significant and growing problem and one that calls into question the view that Pacific islanders because of their social networks, traditions and subsistence lifestyle are protected from poverty. Data on hunger was similarly found to be incomplete but indicated that a significant proportion of children are undernourished and that prevalence of underweight children is relatively constant or increasing in at least four Pacific island countries (PICs).

The report found that poverty reduction is clearly of relevance to the Pacific and data needs to be complete and support analysis of differences between countries. It also needs to address the non-economic aspects of hardship in order to take into account subsistence and traditional resources and social networks which are so important for many Pacific islanders. In relation to hunger there is a need to develop additional indicators and gather information on family settings and hence the causes of childhood malnutrition. 


\section{Millennium Development Goal 2: Achieving Universal Primary Education}

The goal of achieving universal primary education measured in terms of enrolment was reported as being reached or on the way to be achieved in many Pacific island countries. But the challenge of providing universal primary education that effectively addresses both individual and societal needs remains and is growing. There is growing evidence from across the region that a large number of youth leave school without the adequate life skills and are unable to either further their education or gain employment. Contributing problems include alienation of poor performing students and poor financial support for basic education. Despite the commitment of Ministers of Education to improving all aspects of the quality of education and ensuring excellence for all, progress towards this goal is not measured effectively through existing MDG education related indicators.

The report recommended the development of alternative indicators for the Pacific to measure the proportion of pupils who start grade 1 and reach grade 6 which is the primary school completion rate in the Pacific, in addition to developing key indicators to capture quality and relevance of education. It is not clear whether this is in fact being done. However, there is the opportunity at regional level for new education frameworks such as revisions to the Forum Education Ministers Action Plan to be developed with these recommendations in mind in order to better measure improvements in educational outcomes such as essential life skills and success in providing skills required for employment and livelihood in the traditional subsistence economy.

\section{Millennium Development Goal 3: Promote Gender Equality and Empower Women}

Significant achievements have been made in some PICS with respect to gaining equal access to educational opportunities for women, and the importance of gender issues and equality are now widely recognised in the region, and increasingly reflected in policy documents. Despite this progress serious challenges remain. Females are distinctly underrepresented in many PICs at one or more educational levels. Census data on literacy levels indicates relative gender equality, but the measure used is not rigorous, and more discerning indicators are needed to accurately measure literacy levels and gender differences. Data on women's representation in the non-agricultural sector of the labor market showed increases in women's share in some PICs, but country specific research suggests women continue to be at a significant disadvantage in terms of wages, working conditions and overall opportunities. Women were 
severely underrepresented in national parliaments across the Pacific, holding and average of 5.5 per cent of seats at the time. Today the Pacific (excluding Australia and New Zealand) has the lowest levels of female representation in parliaments when compared to other regions of the world.

Recommendations around Goal 3 included: to improve gender related analysis of the education sector; and the need to adopt indicators that measure literacy in its broadest sense, and in ways that are relevant to PICs, e.g. basic legal literacy and business literacy; to develop indicators that measure both the participation and relative status of women in the labor market; and encouraged countries to include additional indicators to parliamentary representation in order to measure the relative status of women in other areas of decision making such as the local government level or in the public service.

Moving beyond policy level successes (which may have gone backwards since 2004 as indicated by recent country indications in the Beijing +15 review process) the need for further research and evidence to gauge the effect of inequality on broader development progress was highlighted in order to enable analysis that can identify where assistance should be targeted. SPC is pursuing work in this area and is working with six countries to assess the capacity of governments to mainstream gender in all aspects of national development. Other work has started to improve the compilation and use of gender statistics in national planning and development processes; and there are plans to research the cost to governments of neglecting targeted investment in gender equality. There have been many other initiatives both regional and bilateral aimed at improving various dimensions of gender equality at country level with support from UNIFEM (United Nations Fund for Women), UNFPA (United Nations Population Fund), and the Government of Australia in particular. Major focus has been in the areas of governance and women's legal and human rights women's political representation and violence against women.

\section{Millennium Development Goal 4: Reduce Child Mortality}

The findings in 2004 stated that children's health status in the region has improved significantly from the 1960s as a consequence of health programs focusing on maternal and child health, much the same as the 2009 report and under -five mortality rates are below the average for all developing countries therefore the targets may not be applicable to all PICs. However, child and infant mortality and overall health remain serious issues in all PICs as evidenced by significant rates of underweight children. The report noted significant under reporting of infant deaths in some PICs, and highly variable rates in countries with small populations, in addition to highlighting the need for disaggregated 
Politics, Development and Security in Oceania

data that will allow analysis of sub-national differences and determination of various causes of infant and child mortality. Recommendations included the need to enhance cooperation between the health sector and national statistics offices to improve coverage and accuracy of statistics relating to infant, child and maternal health and mortality and for increased support for nutrition programs focusing on infants, mothers and children especially in countries with high malnutrition and high infant mortality.

\section{Millennium Development Goal 5: Improve Maternal Health}

Again, the 2004 report notes that maternal health status has improved significantly in the recent decades and figures for the Pacific island region are below the average for developing countries (440 per 100,000 live births) and all except Solomon Islands and Papua New Guinea are below the average for the Asia Pacific region (110). Despite these improvements, maternal health remains a serious concern across the region. Leading causes of maternal death were similar to those reported globally: postpartum hemorrhage, preeclampsia, obstructed labor, puerperal sepsis, and complications of unsafe abortion. Important indirect causes include anemia and malaria (the latter in PNG and Solomon Islands.) Improving the level of obstetric care is a priority in all PICs, in addition actions need to be taken to expand overall access to health care during pregnancy and childbirth, and to improve pre-natal care standards. Early first visits for medical checks during pregnancy and regular ongoing health care thereafter are important in ensuring the health of both mothers and children.

Maternal health in all PICs will also benefit from strategies that focus on: improving nutrition for women and girls (including prevention of micronutrient deficiencies and anemia), combating infectious and non-communicable diseases, addressing reproductive health needs, and addressing violence against women.

In relation to tracking maternal health indicators, recommendations included the need for other process indicators to measure progress in providing obstetric care, and maternal health more generally. Information requirements and issues included: common definitions to measure the proportion of deliveries with skilled attendants trained in the delivery of emergency obstetric care (EmOC); indicators of the number of facilities offering EmOC and their geographic distribution within each PIC; indicators for the percentage of women with complications treated in EmOC facilities, and for caesarean section and fatality rates; age specific fertility rates e.g. rate of teenage pregnancy; rate of births in private clinics as opposed to public hospitals or health centers; nos. of overseas referrals; data regarding the percentage of women attending antenatal care at 
least once during pregnancy, percentage of women receiving postnatal care, and the percentage of anemic women (antenatal and postnatal care are important to monitor birth weight and complications during pregnancies).

Other recommendations included: the undertaking of a regional needs assessment relating to maternal mortality and morbidity (with assessment of emergency obstetric facilities), and systems instituted to perform maternal and perinatal reviews; training of health practitioners and health service providers (including midwives and traditional and village birth attendants) in the utilisation of evidence-based obstetrical protocols and guidelines relating to delivery care; raising awareness of attendants on the importance of birth and death registration (as required under the Convention on the Rights of the Child) and of the importance of early (and regular) pre-natal care visits. In addition to training there is a need for the development and upgrading of infrastructure, particularly in rural areas (including communications, medical facilities and equipment), and provision of adequate supplies.

\section{Millennium Development Goal 6: Combat HIV/AIDS, Malaria and Other Diseases}

It is commonly known that the Pacific faces a 'double burden' of infectious and non-communicable disease (NCD) which impacts on the health of individual and populations and has the potential to significantly affect broader social and economic development as well. Addressing them is critical to development progress.

In relation to HIV/AIDS, although prevalence was low (outside of PNG) when compared to global levels, levels of infection were of serious concern and there was a real risk of substantial and rapid increase. Data was unavailable for a number of indicators e.g. condom use rate of the contraceptive prevalence rate; condom use at last high risk sex; no. of children orphaned by HIV/AIDS. Recommendations included: (i) working with NSOs and Ministries of Health to select HIV related indicators (such as access to affordable drugs) that are relevant at regional and national level for which data will be available; and (ii) coordinate the effort across HIV programs for data comparability. This is being addressed through new and ongoing regional programs addressing HIV.

Malaria is a significant disease burden in the Papua New Guinea, Solomon Islands and Vanuatu where it is endemic but reliable data on either incidence or prevalence was not available. Additional indicators should be adopted that will allow a more accurate assessment of progress. This issue is beginning to be addressed through support from the Global Fund. Again, NSOs and Ministries of Health need to work together to select relevant indicators and ensure that data is available as part of this process. 
Politics, Development and Security in Oceania

Tuberculosis (TB) is a serious health problem in a number of countries and there is increasing concern over the emergence of multi-drug resistant TB, and coinfection with AIDS. Although the Directly Observed Treatment Short Course (DOTS) strategy has been widely implemented across the Pacific, access to DOTS is not universal in all PICs. As a result an important indicator to monitor is the population accessible to DOTS. Recommendations include: to adopt an additional TB indicator measuring the proportion of the population with access to health centers that use the DOTS strategy; and increase efforts to limit the spread of drug resistant TB.

Given the prevalence of NCDs in the Pacific the report recommended that PICs develop NCD targets and indicators under Target 8 of this goal even though they are not monitored globally. Relevance of monitoring specific NCDs and NCD risk factors will vary from country to country and implemented through national NCD plans supported by WHO and the SPC.

\section{Millennium Development Goal 7: Ensure Environmental Sustainability}

In summary there has been no systematic effort to monitor the state of the environment despite a number of reviews. Consequently, the ability to effectively monitor environmental changes is weak. Data from which environmental change may be monitored and on which management decisions can be based is scarce, with time series information generally not available.

The 2004 report noted that deforestation continuing at an unsustainable rate and a lack of up to date information prevents any comprehensive assessment of the status of different forest types and land uses important to PICTs. Protected areas have expanded in size and number but again the data not accurate on their status, the use of traditional cultural practices to protect marine and land resources - these may not be included in internationally accepted protected area definitions; threats to biodiversity affect many species or habitats generally and cannot be effectively addressed through protected area designation.

Global warming and climate change are very important issues for PICs and the region is committed to reducing carbon dioxide emissions per capita, which are already typically well below the average for Asia and Oceania. All PICs have committed to phasing out the use of ozone-depleting substances by the end of 2005, and to increasing the use of alternative energy sources. The sustainability of biomass resources is recognised to be an important issue, particularly because only 30 per cent of the region's population has access to electricity. The Pacific Islands Energy Policy and Plan recognises the fundamental importance of access 
to energy for economic and social development, but also the need to ensure that energy use and resource development is undertaken in a way that is compatible with the special needs and circumstances of PICs.

Access to safe water is vital for health and human development. The data quoted in the report is part of a significant body of evidence that indicates sustainability of water resources is a significant and increasing problem in much of the region as a consequence of drought, population growth, increasing water demand for tourism, agriculture and industry, and aging water systems. The problems are not new. Many of these issues were identified as concerns over 20 years ago. Nevertheless, comprehensive, comparable data to evaluate access to fresh water on a regional basis are scarce. In many PICs, knowledge about the type, extent and sustainable yields of surface and groundwater resources is very limited. This is true even on islands where water shortages occur as s result of demand exceeding supply during drought periods. Problems in the knowledge base include: a lack of baseline water resource assessments; insufficient regular monitoring of water resources; limited analysis and interpretation of water resources data for planning and design of water resources development projects, and for management of catchments.

Access to basic sanitation that serves to protect human health and environmental quality (including water resource quality) is of vital importance for both human health and development making the target of proportion of urban population with access to improved sanitation and the associated indicator very relevant for PICs. Inadequate sanitation systems currently have a significant impact on water quality and human health in many PICs, making collection and analysis of relevant sanitation related data a high priority.

In general the report found it difficult to make an assessment of progress towards Goal 7 targets from existing quantitative data. Data are not uniformly available and not of consistent quality. In a number of cases modifications are needed to the standard indicator definitions (and/or changes needed to the indicators themselves), if a meaningful assessment is to be made. There is strong political will within the region to environmental sustainability and good regional cooperation in all areas covered under this goal as evidenced by the various regional frameworks and action plans. Relevant regional environmental priorities not mentioned in the MDG which need to be included are: solid waste management and sea level rise. 


\section{Millennium Development Goal 8: Develop a Global Partnership for Development}

It is clear that the primary challenge for PICs in achieving the MDGs lies in securing the necessary extent of external support through overseas development assistance, foreign direct investment, trade and development partnerships. ODA has been relatively high for most PICS given their small populations. Cost of aid delivery is high due to the dispersed and geographic nature of the region. The 2004 report noted the declining levels of ODA from Australia and New Zealand, FDI declines as a result of inefficient bureaucracies, the high cost of doing business, inconsistent policies, poor access to land and a lack of skills in the investment promotion area. The situation with respect to ODA, FDI and trade in the Pacific highlights the need for ongoing dialogue regarding the provision of development support to the region. Recommendations included: the need to conduct research on aid effectiveness in the Pacific; strengthening civil society partnerships in the delivery of aid particularly in targeting the poor and vulnerable groups; the need for both donors and countries to focus on capacity building and to support policies and reforms that enhance the quality and responsiveness of development institutions; further the need to rely on country mechanisms in the provision on aid; to pool resources and to develop common reporting and accountability standards.

\section{Conclusion}

The 2004 report demonstrated that substantial progress had been made against certain indicators and the Pacific region will meet some MDG targets. It also showed that the Pacific region compares relatively favorably to other regions in a number of areas - particularly in education and health. Although, progress varied greatly across the region and even within countries, the progress that has been made towards some goals clearly illustrated the efforts by the region's people, governments and development partners have resulted in positive development outcomes. However, much greater efforts is needed if the Pacific is to achieve the MDGs by 2015 and in some areas such as health there is a real risk that the some of the region's gains could be reversed.

So where are we in 2009, five years later and as we approach 2015? The Australian government's recent report on Tracking development and governance in the Pacific provides an update on MDG progress in the Pacific which in short, shows that not much has changed but sets the alarm bells ringing that the Pacific as a region is unlikely to meet the MDGs by 2015. 
Rising poverty is more evident; chronic hunger and poor nutrition persists; economic growth was good but concentrated in a few countries with the global recession affecting all countries and reducing opportunities for gains from this growth. The gains had not necessarily led to a reduction in poverty. Despite high levels of children entering the school system there are still serious concerns for the numbers of children out of school and not completing primary school. Gender equality improvements are mixed with women's participation in political decision-making still very low throughout the region. Reports of very high levels of gender based violence in some countries indicate that gender inequality is prevalent at the very core of societies in the Pacific and needs to be addressed as a fundamental development issue. Despite progress in combating Malaria, the health MDGs need serious attention with NCDs now the leading cause of death in 8 countries in the region, and only three countries on track to reduce maternal mortality by three-quarters in 2015. Improved service provision continues to be high priority as while addressing the social determinants of these health situations through education, in particular of girls and women and through the empowerment of women and communities. Environmental threats are intensifying and issues such as climate change have the potential to affect progress in achieving the other MDG. All strategies to adapt and mitigate the effects of climate change on the health and wellbeing of Pacific island people must be designed, planned and implemented with involvement of the people who are most affected, including women and young people.

\section{What Needs to Change in Order For Us to Get Back on Track?}

The most critical change needs to come in the way that Pacific island country governments manage, use and report on resources acknowledging that many countries are already making significant investments in their own development. However, the region's track record on MDG progress, makes it clear that these resources are not being used as effectively as they could be nor are they benefiting those who need them the most - the growing numbers of poor and disadvantaged in our countries including those lacking services and opportunities for livelihood and wellbeing in the rural and outer island areas. Governments need to focus on getting resources and services to these people if there is to be change. This must be the priority. Tracking MDG progress through these regional and country reviews provides valuable direction on what to do and how to go about doing it. Countries must follow through on their political commitment and resolve to do this within their country context in consultation with their people and development actors. 
Politics, Development and Security in Oceania

\section{References}

Secretariat of the Pacific Community. 2004. Pacific Islands Regional Millennium Development Goals Report 2004. Noumea, New Caledonia. 